\title{
Papular amyloidosis and leonine facies: about two
}

\section{cases}

\begin{abstract}
Papular amyloidosis or amyloid lichen is a form of localized skin amyloidosis potentially rare. Its mechanism is poorly known. There are localized and hereditary systemic and cutaneous forms. Papular amyloidosis is a form of localized cutaneous amyloidosis. It is manifested by papules, fleshy or brown, smooth or very hyper-keratotic, very pruriginous, simetric and sitting electively on the anterior surfaces of the legs and extending to the calves and back of the feet, often excoriated by the intensity of scraping. Leonin facies can be observed in systemic amyloidosis but it has not been described in lichen amyloid. We report 2 cases of this association.
\end{abstract}

Keywords: amyloidosis, lichen amyloidosis, papular amyloidosis, leonine facies
Volume 3 Issue $6-2019$

\author{
Kaoutar Achehboune, Sara Oukarfi, Zakia \\ Douhi, Hanane Baybay, Fatima Zahra \\ Mernissi \\ Department of Dermatology, Venereology Hospital University, \\ Morroco
}

Correspondence: Kaoutar Achehboune, Department of Dermatology, Venereology Hospital University, Morroco, Email achehboune.kaouta@gmail.com

Received: October 29, 2019 | Published: December 30, 2019

\section{Introduction}

Papular amyloidosis or Lichen amyloidosis is a form of localized skin amyloidosis potentially rare. Its mechanism is poorly known. The leonine facies can be observed in systemic amyloidosis but it has not been described in lichen amyloidosis. We report two cases with a leonine facies.

\section{Case report I}

A 65-year-old man, diabetic, who had very itchy lesions in the limbs and trunk evolving since 14 years, the dermatological examination had found pigmented papules with keratotic surface in the limbs and cupboards pigmented at the trunk and a typical leonine facies without sensitivity disorder including no hyposensitivity and no sweating disorder (Figure 1). Moreover, there was no systemic involvement, in particular hepatic or cardiac or renal. The histo-pathological study was in favor of papular amyloidosis (lichen amyloidosis). The biological

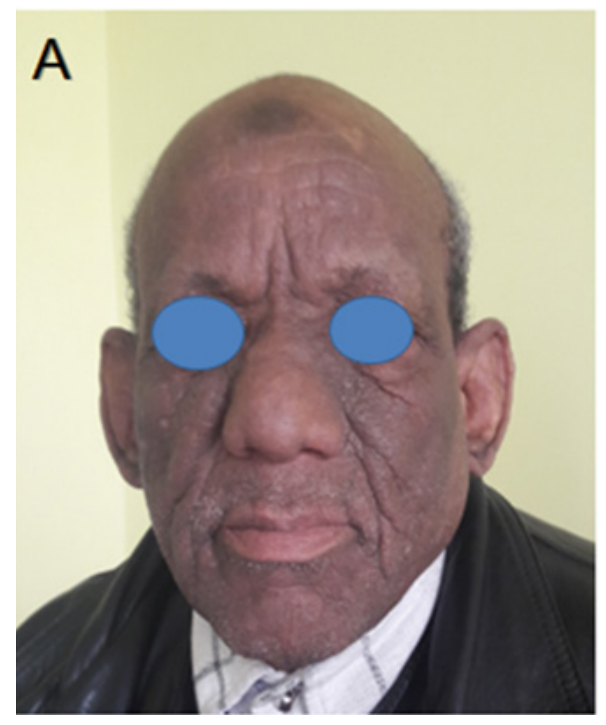

Figure I (A) Facies léonin. (B) Papules pigmentées a surface keratosique. and radiological examination was performed to search a systemic attack was normal .The patient was treated with dermocortoids with improvement in pruritus and body lesions with persistence of leonine facies.

\section{Case report 2}

A 45-year-old woman, presenting confluent patches of pruriginous and erythematous papules and nodules, with keratotic surface confluent on the trunk without sensitivity or sweating disorder. A Léonin facies, coarse, with thickened pleated facial skin, with accentuation of wrinkles (Figure 2). There was no Phanerian involvement, with no other organ involvement, especially cardiac or hepatic. The anatomopathological study was in favor of lichen amyloidosis. There was no systemic damage to the balance sheet. The patient was placed on dermocorcoide with $30 \%$ trichloroacetic acid contact with short course systemic corticosteroids with good improvement.

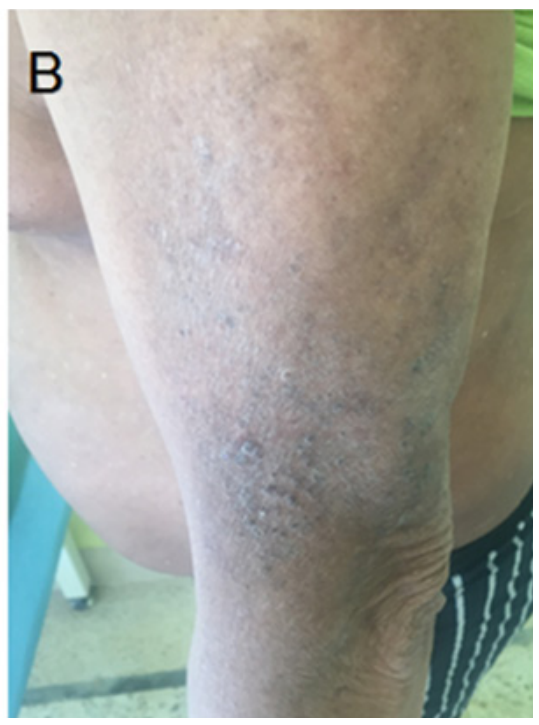



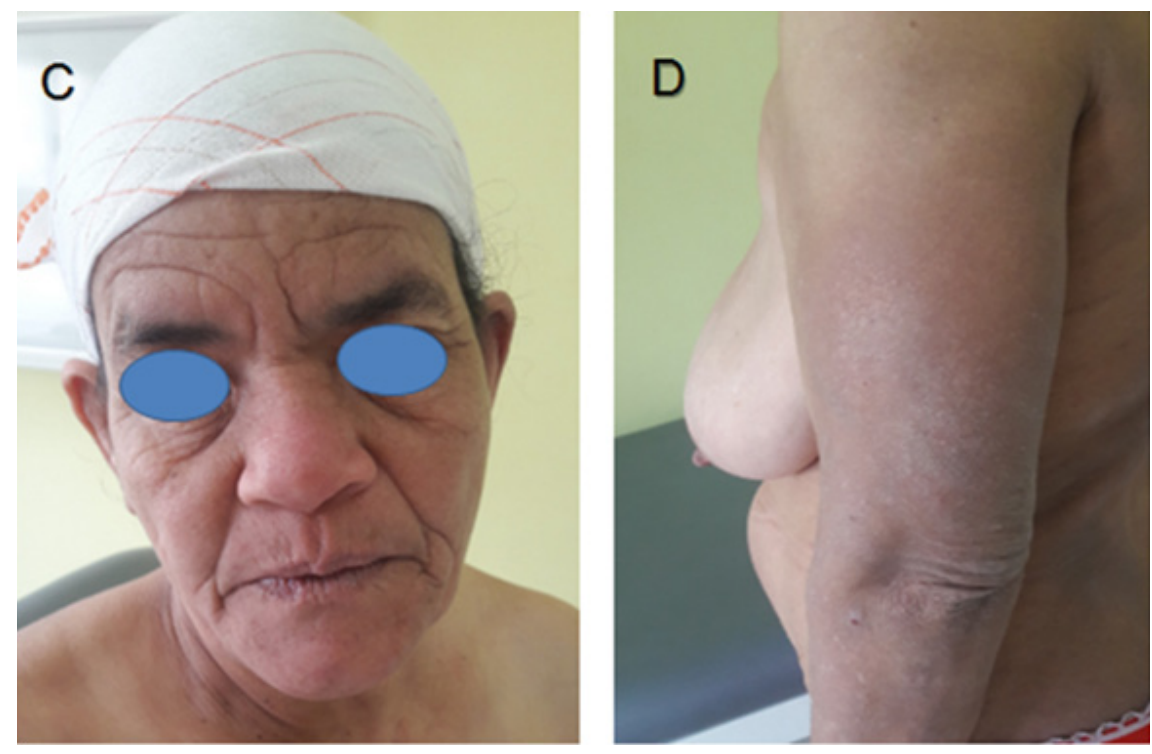

Figure 2 (C) Facies léonin- like. (D) Papules pigmentées a surface keratosique.

\section{Discussion}

Amylosis are a group of pathologies that correspond to extracellular deposits of fibrillar proteins, arranged in "pleated sheet" according to the spatial configuration beta with a dye affinity to Congo red. ${ }^{1}$ Its mechanism is poorly known. There are localized and hereditary systemic and cutaneous forms. Papular amyloidosis is a form of localized cutaneous amyloidosis. ${ }^{2}$ It is manifested by 1 to $3 \mathrm{~mm}$ papules, flesh-colored or brown in appearance, smooth or hyper-keratotic, very pruriginous, sitting electively on the anterior surfaces of the legs and extending to the calves and back of the feet. With symmetrical disposition, often excoriated by the intensity of scraping. ${ }^{2-6}$ The leonine facies can be observed in systemic amyloidosis, ${ }^{6}$ but it has not been described in amyloid lichen. We report two cases for the first time to our knowledge. Lichen amyloidosis is a condition that is often difficult to treat and limits quality of life because of intense pruritus and unsightly skin lesions. ${ }^{5}$ The treatment of amyloidosis remains a challenge for the dermatologist given the presence of several therapeutic modalities (dermocortoids, Tacrolimus, YAG laser, $\mathrm{CO}_{2}$ laser, Isotretinoine, Cyclosporine, Phototherapy and others) but there is no gold standard, the treatment goal is mainly the improvement of symptoms. ${ }^{4}$

\section{Conclusion}

Papular amyloidosis is a local cutaneous form of amyloidosis. The leonine facies can be a clinical manifestation of this localized form.

\section{Conflicts of interest}

The authors do not declare any conflict of interest.

\section{Acknowledgments}

None.

\section{Funding}

None.

\section{References}

1. Modiano P. Amyloses cutanées. EMC Dermatologie. 2015;10(2):1-10.

2. Ladizinski B, Lee KC. Lichen amyloidosis, CMAJ. 2014.186(7):532.

3. Modiano P. Amyloses cutanées, Ann Dermatol Venerol. 2005;132:62-70

4. Weidner T, Illing T, Elsner P. Primary Localized Cutaneous Amyloidosis: A Systematic Treatment Review. Am J Clin Dermatol. 2017;18(5):629642.

5. Robinson CG, Jahan-Tigh RR. Successful Treatment of Lichen Amyloidosis with Trichloroacetic Acid Peels. Dermatol Surg. 2019; 45(6):854-857.

6. Mason AR, Rackoff EM, Pollack RB. Primary systemic amyloidosis associated with multiple myeloma: a case report and review of the literature. Cutis. 2007;80(3):193-200. 